\title{
The quantification of bisphenols and their analogues in wastewaters and surface water by an improved solid-phase extraction gas chromatography/mass spectrometry method
}

\author{
Magda Caban $^{1}$ (D) Piotr Stepnowski ${ }^{1}$
}

Received: 12 January 2020 / Accepted: 29 April 2020 / Published online: 16 May 2020

(C) The Author(s) 2020

\begin{abstract}
The study focused on the application of GC in the quantitative analysis of bisphenols and their analogues (12 analytes), and the improvement of solid-phase extraction for the whole water analysis of complex water samples. The role of silylation in the qualitative and quantitative analysis of bisphenols was investigated. Partial degradation occurred for selected targets during hot injection with the presence of a silylation agent. A PSA (primary and secondary amines) sorbent placed on the top of the solidphase extraction (SPE) column sorbent was found to be a matrix component trap, mostly for humic acids. The whole water analysis was performed by washing the filters with methanol and recycling the extract to the sample. The validation of SPE-GC/ MS(SIM) gave limits of detection of $1-50 \mathrm{ng} / \mathrm{L}$ for ten target bisphenols with a method recovery of between 87 and $133 \%$. The application of the method was tested by the analysis of wastewater sampled from three wastewater treatment plants located in Poland, and municipal surface waters. The only analytes found were BPA and BPS, within the range of 16-1465 ng/L and < MDL-1249 ng/L in wastewater, and 170-3113 ng/L and < MDL-1584 ng/L in surface water, respectively.
\end{abstract}

Keywords Bisphenol A $\cdot$ Bisphenol analogues $\cdot$ Multi-component analysis $\cdot$ Wastewater monitoring $\cdot$ Silylation

\section{Introduction}

The increase in anthropogenic pressure on the environment with regard to hazardous substances is strictly connected with industrial development. However, the introduction of new materials, especially synthetic polymers, gives humanity new possibilities for development. The main applications of synthetic polymers are food packaging, the building industry, the electrical and electronics industry, daily life items (furniture, toys, fibers, clothes), and many more. One of the compound which can be found in plastics is bisphenol A (BPA), a chemical with endocrine-disrupting potential (Corrales et al.

Responsible Editor: Ester Heath

Electronic supplementary material The online version of this article (https://doi.org/10.1007/s11356-020-09123-2) contains supplementary material, which is available to authorized users.

Magda Caban

magda.caban@ug.edu.pl

1 Department of Environmental Analysis, Faculty of Chemistry, University of Gdansk, ul. Wita Stwosza 63, 80-308 Gdańsk, Poland
2015; Vahedi et al. 2016; Murphy et al. 2019). BPA, discovered in 1891, is a monomer for the synthesis of selected polycarbonates (PC), epoxy and vinyl ester resins, and polysulfones. Most of the items containing BPA are made from rigid, transparent and temperature-/pressure-stable polymers. Epoxy resins are used mostly as protective layers, for example, inside cans and water pipes, or in paper used in sales receipts. In 2015, BPA production was 4 million tonnes, which was the largest amount for a single compound (Almeida et al. 2018). Moreover, derivatives and analogues of BPA are also produced. Currently, BPA is a compound of high interest because it is classified as an endocrine-disrupting chemical (EDC) and is proven to leach from packaging materials into food. "BPA-free" items are marketed as safe. Nevertheless, although the substitution of BPA by BPA-like compounds can be achieved (Chen et al. 2016), statistics of its production and use are hard to find. What can be found in the literature is that often, instead of BPA, such analogues are used as bisphenol S (BPS), bisphenol F (BPF), and bisphenol AF (BPAF) (Warner and Flaws 2018). In the thermal paper, 19 bisphenols (BPs) were identified (U.S. Environmental Protection Agency 2015). Scientific reports show the similar 
endocrine-disrupting potential of other bisphenols (Warner and Flaws 2018; Wang et al. 2019) and the ecotoxicological risk of mixtures of bisphenols (BPs) (Owczarek et al. 2018). BPF was found to exhibit genotoxicity (Cabaton et al. 2009). All these facts raise concern regarding the safe use of alternatives to bisphenols. In addition to human health safety, the environmental impact is also observed (Corrales et al. 2015). The main route of BPs into the environment is wastewater (WW), both residential and industrial. The detection frequency and concentration level are generally known for BPA (up to $84,000 \mathrm{ng} / \mathrm{L}$ in raw WW) (Gercken et al. 2018; Wang et al. 2019), while for BPA-like compounds, only a few reports have been presented, which found concentrations were much lower (dozens to hundreds ng/L) (Sun et al. 2017; Česen et al. 2018; Wang et al. 2019; Xue and Kannan 2019). This limitation can be caused by problems in application of one technique for the problematic analysis of several BPs in one run. LC-MS and LC-MS/MS are often used for such analyses, but some troubleshooting can occur (for example, the presence of BPA in the solvents and the system, the instability of some analogues in solutions) (Wilczewska et al. 2016; Szczepańska et al. 2019). GC-MS was rarely used for the analysis of BPA and its analogues because of the need for silylation. Nevertheless, this process of derivatization could be beneficial for the quantification of organic pollutant traces in natural waters (Caban et al. 2011; Sadkowska et al. 2017). To date, the advantages and limitations of the application of GC/MS for the quantification of BPs have not been investigated.

The aim of this work is to verify the use of the GC-MS technique in order to perform the quantification of twelve BPs (targets presented in Table S1, Supplementary Information). The next objective was to test a modification of solid-phase extraction (SPE) for whole water analysis in samples with a high content of dissolved organic matter, in which BPs can be adsorbed (in most available reports, only the free fraction was determined). Thanks to this, it was aimed to examine the current level of BPs in an exemplary urban area samples in which such a study has never been performed before, but it is known to be strongly impacted by human activities. In addition, the WW samples were taken from three wastewater treatment plants (WWTP), differentiated in size and technologies, in order to check the presence of BPs other than BPA (rarely investigated).

\section{Experimental}

\section{Chemicals and materials}

Standards of BPs (BPE, bisphenol E; BPC, bisphenol C; BPADMC, bisphenol A dimethacrylate; BPBP, bisphenol BP; BPF, bisphenol F; BPA-DGE, bisphenol A diglycidyl ether; BPADAC, bisphenol A diacetate; BPZ, bisphenol Z; BPFL, bisphenol FL; BPAF, bisphenol AF; BPS, bisphenol S; BPA, bisphenol A; BPA-D16, deuterated bisphenol A) were purchased from Sigma-Aldrich, with a minimum of $98 \%$ purity. Stock solutions were prepared in methanol (HPLC purity, POCH, Poland) and stored at $-20^{\circ} \mathrm{C}$. Working solutions were also prepared in methanol. During the experiments, all equipment used was made of glass or Teflon (except the SPE cartridge, made from polypropylene, PP). Derivatization was performed using a BSTFA $(\mathrm{N}, \mathrm{O}$-bis(trimethylsilyl)trifluoroacetamide $)+$ 1\%TMCS (trimethylchlorosilane) reagent (Synthese North, Germany).

\section{Pretreatment and solid-phase extraction of water samples}

Several sets of solid-phase extraction (SPE) were tested (Table 1). The differentiating factors were (a) the addition of humic acids (HA, $5 \mathrm{mg} / \mathrm{L}$ ) as representatives of dissolved organic matter, (b) the filtration of the sample before SPE using glass fiber filters, (c) the washing of the filters with 2 $\times 5 \mathrm{~mL}$ of methanol and adding the obtained solution to the water sample, (d) the addition of $50 \mathrm{mg}$ of the PSA (primary and secondary amines, Supelco) sorbent on the top of the Strata-X column ( $200 \mathrm{mg} / 3 \mathrm{~mL}$, Phenomenex) to retain some of the water sample matrix. The internal standard (IS) was added to the water samples before any treatment of the water sample. For the determination of the extraction efficiency, the mixture of analytes was added to obtain a concentration of 4 $\mu \mathrm{g} / \mathrm{L}$ in the samples. The SPE protocol was as follows: prewashing of the column with $3 \mathrm{~mL}$ of methanol, followed by the application of $3 \mathrm{~mL}$ of deionized water, the application of $100 \mathrm{~mL}$ of the sample using vacuum assistance, washing with $3 \mathrm{~mL}$ of $5 \%$ aq. methanol, drying, washing with $3 \mathrm{~mL}$ of hexane (HPLC grade), drying, and elution with $3+3 \mathrm{~mL}$ of methanol. The extract was concentrated and transferred to chromatographic vials and the solvent was totally removed. The dry extracts were stored at $-20^{\circ} \mathrm{C}$.

\section{Derivatization and GC/MS(SIM) analysis}

For derivatization, the solvent was removed from the extract, $50 \mu \mathrm{L}$ of the reagent was introduced and the vials were vortex mixed. The reaction of trimethylsilyl (TMS) derivatives synthesis was at $30{ }^{\circ} \mathrm{C}$, while the time was $30 \mathrm{~min}$. The optimization of these parameters was performed for BPs, and the results show that prolonging the reaction time to $60 \mathrm{~min}$ or increasing the temperature to $75^{\circ} \mathrm{C}$ and $90{ }^{\circ} \mathrm{C}$ did not change the reaction success (the surface area of the chromatographic peak was stable, Fig. S1 in Supplementary Information). After derivatization, the post-reaction solution was transferred to glass inserts closed by caps with red Teflon/silicone membranes, and the samples were subjected to analysis using the GC/MS equipment (GC-2010 Plus coupled to a GCMS-QP 
Table 1 The sets tested under the optimization of solid-phase extraction (SPE) (HA $-5 \mathrm{mg} / \mathrm{L}$ of humic acid in the water sample), PSA - sorbent based on primary and secondary amines)

\begin{tabular}{|c|c|c|c|}
\hline Sets & $\begin{array}{l}\text { Filtration } \\
\text { before SPE }\end{array}$ & $\begin{array}{l}\text { Washing of the filters with } \mathrm{MeOH} \text { and the addition of } \\
\text { methanolic extract to the water sample }\end{array}$ & $\begin{array}{l}\text { The addition of PSA on } \\
\text { top of the SPE column }\end{array}$ \\
\hline $\begin{array}{l}1 \\
1 \mathrm{HA}\end{array}$ & Yes & No & No \\
\hline $\begin{array}{l}2 \\
2 \mathrm{HA}\end{array}$ & Yes & Yes & No \\
\hline $\begin{array}{l}3 \\
3 \mathrm{HA}\end{array}$ & Yes & Yes & Yes \\
\hline $\begin{array}{l}4 \\
4 \mathrm{HA}\end{array}$ & Yes & No & Yes \\
\hline $\begin{array}{l}5 \\
5 \mathrm{HA}\end{array}$ & No & No & No \\
\hline
\end{tabular}

2010 SE mass spectrometer (Shimadzu)). The GC parameters were as follows: column $30 \mathrm{~m} \times 0.25 \mathrm{~mm} \times 0.25 \mu \mathrm{m}(\mathrm{ZB}-5$, Zebron), injection $305^{\circ} \mathrm{C}$, constant helium pressure $100 \mathrm{kPa}$, injection volume $1 \mu \mathrm{L}$, splitless per $1 \mathrm{~min}$, temperature program: starting temperature $120^{\circ} \mathrm{C}$ per $1 \mathrm{~min}$, then a rate of 10 ${ }^{\circ} \mathrm{C} / \mathrm{min}$, final temperature $300{ }^{\circ} \mathrm{C}$ per $6 \mathrm{~min}$ (total $25 \mathrm{~min}$ ), autosampler washing solvent-acetone. The transfer line was heated to $305{ }^{\circ} \mathrm{C}$. The MS analysis was performed using the following settings: $\mathrm{EI}(70 \mathrm{eV})$ temperature $200^{\circ} \mathrm{C}$, solvent cut time $5 \mathrm{~min}$, scan $45-800 \mathrm{~m} / \mathrm{z}$, or SIM (selected ion monitoring), 3 scans per second. Instrument calibration and tuning were performed before each sequence run (normally - daily). The qualitative analysis was performed using (a) the characteristic retention time (span of $\pm 0.2 \mathrm{~min}$ ); (b) a min of two $\mathrm{m} / \mathrm{z}$ values, from which one was the quantitative ion and the rest were the confirmation / reference ions; and additionally, (c) the ratio of quantitative ions to confirmation ions (specified for the standards). The quantitative analysis was performed using the internal standard (IS, BPA-D16), introduced to each sample, in the same amount, and plotting the relative response of the analyte to the IS. Calibration was performed by an analysis of the pure standards ( $\mathrm{min}$. six points in the calibration curve, in duplicate) to check the linearity of the MS response in the tested concentration range, and the instrumental detection and quantification limits.

\section{The validation of the SPE-GC-MS(SIM) method}

For the validation of the method, the latest version of the IUPAC (International Union of Pure and Applied Chemistry) guidelines for single-laboratory validation of methods of analysis (IUPAC 2002) suited the purpose of this study, with the support of general EURACHEM guidelines (CITAC/EURACHEM 2002). The validation was performed using the matrix-matched method by spiking the deionized water samples (test portion $100 \mathrm{~mL}$, HA concentration of 5 $\mathrm{mg} / \mathrm{L}$ ) with the BPs to obtain the following concentrations: $1000 \mathrm{ng} / \mathrm{L}, 500 \mathrm{ng} / \mathrm{L}, 100 \mathrm{ng} / \mathrm{L}, 50 \mathrm{ng} / \mathrm{L}, 10 \mathrm{ng} / \mathrm{L}, 5 \mathrm{ng} / \mathrm{L}, 1$ $\mathrm{ng} / \mathrm{L}, 0.5 \mathrm{ng} / \mathrm{L}, 0.1 \mathrm{ng} / \mathrm{L}$ in duplicate during the same day. The IS was added to each of the samples with the same concentration. Then, SPE was performed according to the 3 HA protocol (Table 1). The obtained calibration curves were used for the quantification of BPs in WW and SW samples.

Quality assurance (QA) was performed using a suitable laboratory environment, skilled staff, the calibration and tuning of equipment, and generally good laboratory practice (following EURACHEM (CITAC/EURACHEM 2002)). Quality control (QC) was performed by the analysis of blanks, spiked samples, and duplicates. In order to verify the SPEGC-MS(SIM) method, the following parameters/ characteristics were determined-applicability, selectivity, trueness, and precision. The applicability of the new method was the screening of a whole-water analysis of concentrations of mixtures of BPs (MDL 0.3-1.7 $\mathrm{ng} / \mathrm{L}$ ) in natural waters and wastewater. The selectivity description is as follows: the organic compounds dissolved in water have no impact on quantification; in the blank sample, BPA can be found, with a negligible impact on quantification. Accuracy was determined by trueness and the calculation of precision. Trueness was proved by the spiking/recovery method (no reference material available). Precision was calculated as the relative standard deviation (RSD, \%) of concentrations found after the repetition of spiking. The matrix variation was tested by the spiking/ recovery of deionized water, and raw and treated WW. The method specificity is the analysis of bisphenol-type compounds in the presence of other substances from this group.

For the method quantification limit (MQL), the following parameters were used: the lowest concentration with precision lower than 5\% and method recovery between 70 and $130 \%$, while for the method detection limit (MDL): $\mathrm{MDL}=\mathrm{MQL} / 3$ + signal to noise ratio 3:1. Before each sequence of analysis, a blank (deionized water without the addition of BPs) was analyzed to track the residual of the concentration of BPs in solvents and the reagent use.

In addition to the validation of the SPE-GC/MS(SIM) method, the validation of only the instrumental analysis 
(without the extraction step) was performed to present the $\mathrm{GC} /$ MS possibilities in order of each of the twelve target BPs.

\section{The screening of bisphenols in surface water and wastewaters}

The validated method was tested by the determination of BPs in raw and treated WWs sampled from three WWTPs in north Poland and from surface water (SW) in Gdansk streams and reservoirs. Gdańsk-Wschód WWTP is the biggest in the region with mechanical, biological, and chemical treatment technology (capacity $120,000 \mathrm{~m}^{3} /$ day). The WWTP located in Gniewino is small but also with the same technology (capacity $850 \mathrm{~m}^{3} /$ day). The WWTP in Swarzewo is a small plant with an SBR (sequencing batch reactor, capacity $7000 \mathrm{~m}^{3} /$ day). The 24-h accumulated samples were collected in PE containers in December 2019.

The four grab samples of SW (100 mL of each) were collected in the city of Gdansk (the map of sampling points is presented in Fig. S2, Supplementary Information) in January 2020. Sample 1 was taken from Oruński Stream, sample 2 from Kozacki Stream, and both streams flow into the Świętokrzyska I retention tank, the outflow from which sample 3 was taken. The water flows from the Świettokrzyska I tank to the Świętokrzyska II retention tank, and the water was also taken from the outflow of this reservoir (sample 4). The water from this reservoir ends in a bigger river and finally in the Baltic Sea. The mentioned streams and reservoirs are located inside the city, and their main role is to collect storm water, thereby the presence of BPs is suspected. Furthermore, the Kozacki Stream is partially located under a municipal landfill.

\section{Results and discussion}

\section{Qualitative and quantitative analysis of BPs by GC-MS}

Each of the tested analytes and the internal standard (IS) were analyzed with and without derivatization. Three bisphenol Abased compounds-BPA-DMC, BPA-DGE, and BPADAC - cannot be derivatized by BSTFA, as they do not possess active hydrogen for replacement via silylation. For them, the chromatographic signal areas were similar when they were dissolved in toluene (without derivatization) or the BSTFA reagent. The rest of the analytes did not give signals in samples not subjected to derivatization. In the literature, a method of BPA analysis by GC without derivatization can be found (del Olmo et al. 1997; D.A. Markham et al. 1998; Oca et al. 2013), but using a cool injection technique, such as a programmed-temperature vaporizer or a cool on-column injector. In a modern split-splitless (S/SL) injection of a natural sample extract, it would be problematic to inject into a cool injector. Furthermore, the limits of detection of TMS derivatives are mostly lower than those for underivatized analytes (Caban et al. 2013b). For example, the detection limit obtained in our study was ng/L, while being 1000 times higher $(\mu \mathrm{g} / \mathrm{L})$ for a cool on-column injection of underivatized samples (D.A. Markham et al. 1998) and for the injection of underivatized samples into an S/SL injector heated to 200 ${ }^{\circ} \mathrm{C}$ (del Olmo et al. 1997). The analysis of BPA as a derivative of tert-butyldimethylsilyl (Durán-Alvarez et al. 2009) gives similar limits of detection as in our study.

In the case of BPA-DMC, it was observed that it is possible that methacrylate groups can be detached from native compounds, and the mono-TMS derivative of BPA-monomethacrylate was observed in the chromatogram. The $\mathrm{m} / \mathrm{z}$ value of the molecular mass of such a new compound was $368 \mathrm{~m} / z$, with M-15 as the highest signal on the mass spectra (full spectrum presented in Fig. S3, Supplementary Information). The other signals were 69 and $73 \mathrm{~m} / z$, proving that such a molecule has both a methacrylate and a trimethylsilyl group. The relative intensity of the peak to BPA-DMC was between 2.8 and $23.0 \%$ in three independent samples. In the chromatogram of the sample not subjected to derivatization, the only peak found was underivatized BPADMC. The presence of an additional peak suggests most probably that during derivatization or injection into a hot injector, BPA-DMC was partially decomposed. This reflects the quantification of BPA-DMC - a high quantification limit compared with most BPs and a lower regression coefficient of the curve (Table S2, Supplementary Information). Similarly, BPA-DAC was found to degrade partially with the release of the acetate group, and the obtained product was derivatized into BPA-mono-acetate-mono- $O$-TMS (BPA-AC-TMS, mass spectrum on Fig. S3, Supplementary Information). It is not clear where the degradation occurs - during derivatization or injection into the hot injector. BPA-DGE was also found to have an additional peak coming from the release of the one glycidyl-ether group, so-called BPA-GE. The mass spectrum of the BPA-GE-TMS derivative is presented in Fig. S3 (Supplementary Information). In the case of BPs with two hydroxyl groups subjected to derivatization, no additional chromatographic signals were obtained.

Table S2 (Supplementary Information) presents the selected parameters of the instrumental calibration curve using BPA-D16 as the internal standard (IS). Similar good calibration line regression coefficients, limits of detection, and precision were found for the BPs, despite derivatization being impossible for BPA-DMC, BPA-DGE, and BPA-DAC.

Figure 1 presents the chromatogram of total ion current (TIC) of the GC-MS analysis of the solution of twelve analytes and the internal standard $(2 \mu \mathrm{g} / \mathrm{mL}$, for IS $1 \mu \mathrm{g} /$ $\mathrm{mL}$ ). The retention times of the BPs with only oxygen as a heteroatom depend on the $\mathrm{m} / \mathrm{z}$ values of the molecular ions. The retentions of BPAF and BPS are out of this dependency. 


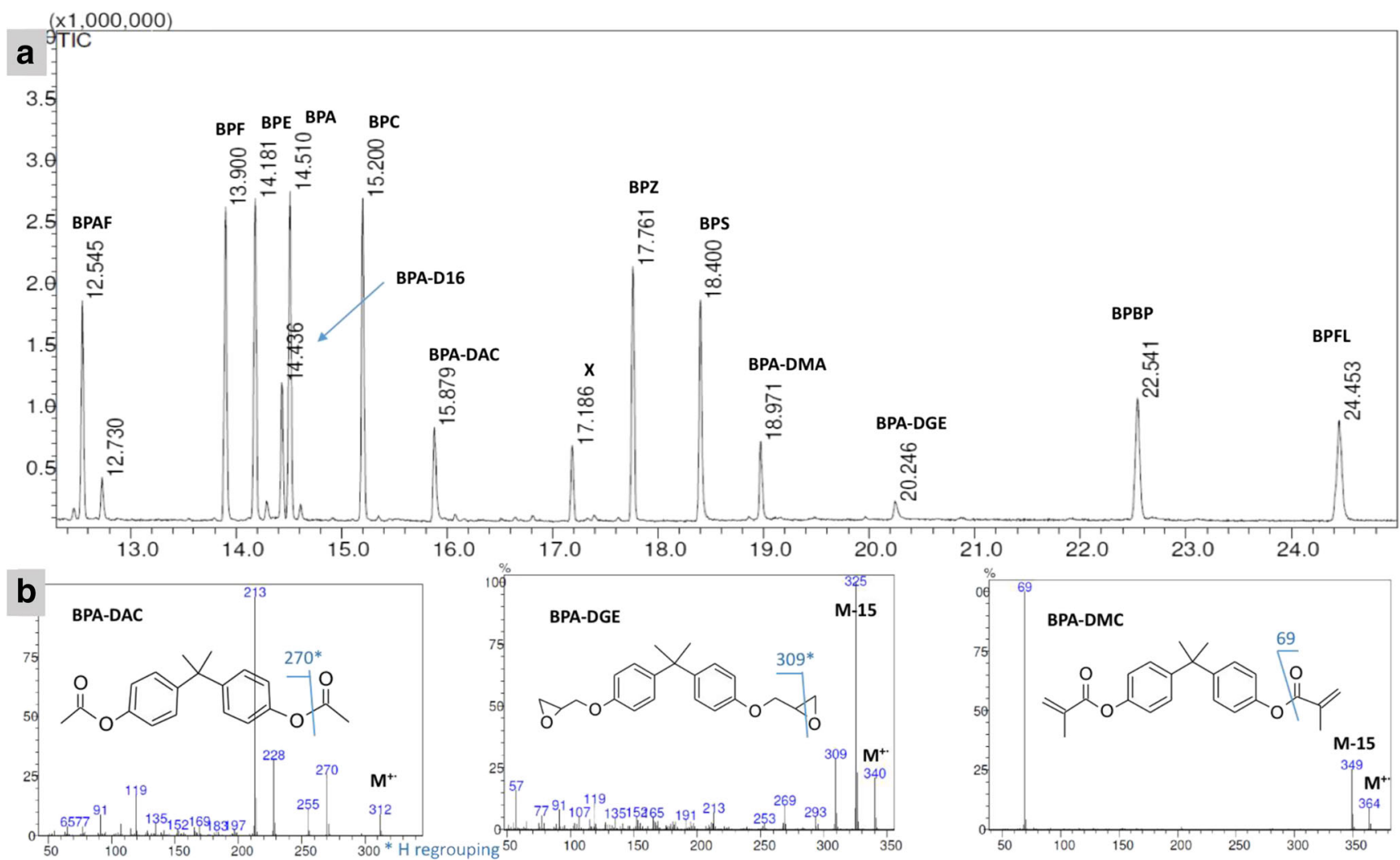

Fig. 1 Part a The GC/MS chromatogram of the analysis of twelve bisphenol analogues together with deuterated bisphenol A. part b The mass spectra of bisphenols which could not be derivatized

BPAF possesses fluorine atoms inside its structure and has the lowest retention times. The lowering of retention times due to the introduction of fluorine atoms was presented by us previously for pharmaceuticals (Caban et al. 2013a, 2013b, 2014). The longer retention time of BPS with respect to BPA as TMS derivatives in the capillary column was mentioned by Cao (Xu-Liang 2019), as a response to the incorrectly presented results of a previous work by Viñas et al. (2010).

The TIC response of the detector (the general potential of analyte ionization) was comparable for BPAF, BPF, BPE, BPA, BPC, BPZ, BPS, BPBP, and BPFL as TMS derivatives (Fig. 2 presents the mass spectra of the TMS derivatives). The response of the detector for BPA-DAC and BPA-DMC was lower compared with the TMS derivatives, which can be caused by the lower opportunity for ionization. The better chromatographic response of silyl derivatives compared with underivatized compounds was presented by several authors, including ourselves (Caban et al. 2013a, 2013b, 2014). For underivatized BPA-DGE, a relatively polar compound, the detector response was much lower, which suggests decomposition or sorption inside the injector/column. Furthermore, previous studies show the instability of such a compound in methanolic solvent (Szczepańska et al. 2019). The lower TIC detector response also reflects a lower response in the selected ion monitoring (SIM) mode, and higher limits of detection for BPA-DMC, BPA-DGE, and BPA-DAC (Table S2 in
Supplementary Information). The fragmentation pattern of the molecular ions was described in Section S1 in Supplementary Information.

Quantification was performed using the selected ion monitoring (SIM) mode. For the purpose of quantification, one of the signals in the spectrum was chosen, named as the quantitative ion. Qualification was performed using the retention times and reference ions (one, two, or three, depending on the compound). The additional confirming factor was the ratio of the quantitative/reference ions. The mentioned ions are presented in Table 2. Despite high intensity, $m / z 73$ was excluded from the SIM mode, as it is not characteristic.

Finally, it can be stated that from the twelve BPs, nine can be successfully analyzed by GC-MS, while three (BPA-DMC, BPA-DGE, BPA-DAC) should rather be analyzed by LC/MS. Nevertheless, it was decided to analyze BPA-DAC in WW samples along with the other nine easily silylated BPs.

\section{Solid-phase extraction performance}

The sorbent inside the Strata-X column is a copolymer of divinylbenzene and vinylpyrrolidone, thereby its adsorption properties are universal, and both polar and non-polar compounds should be retained. In our study, we tested two ways of sample pretreatment-samples were either filtered or not with glass fiber filters; the filters were washed or not with 

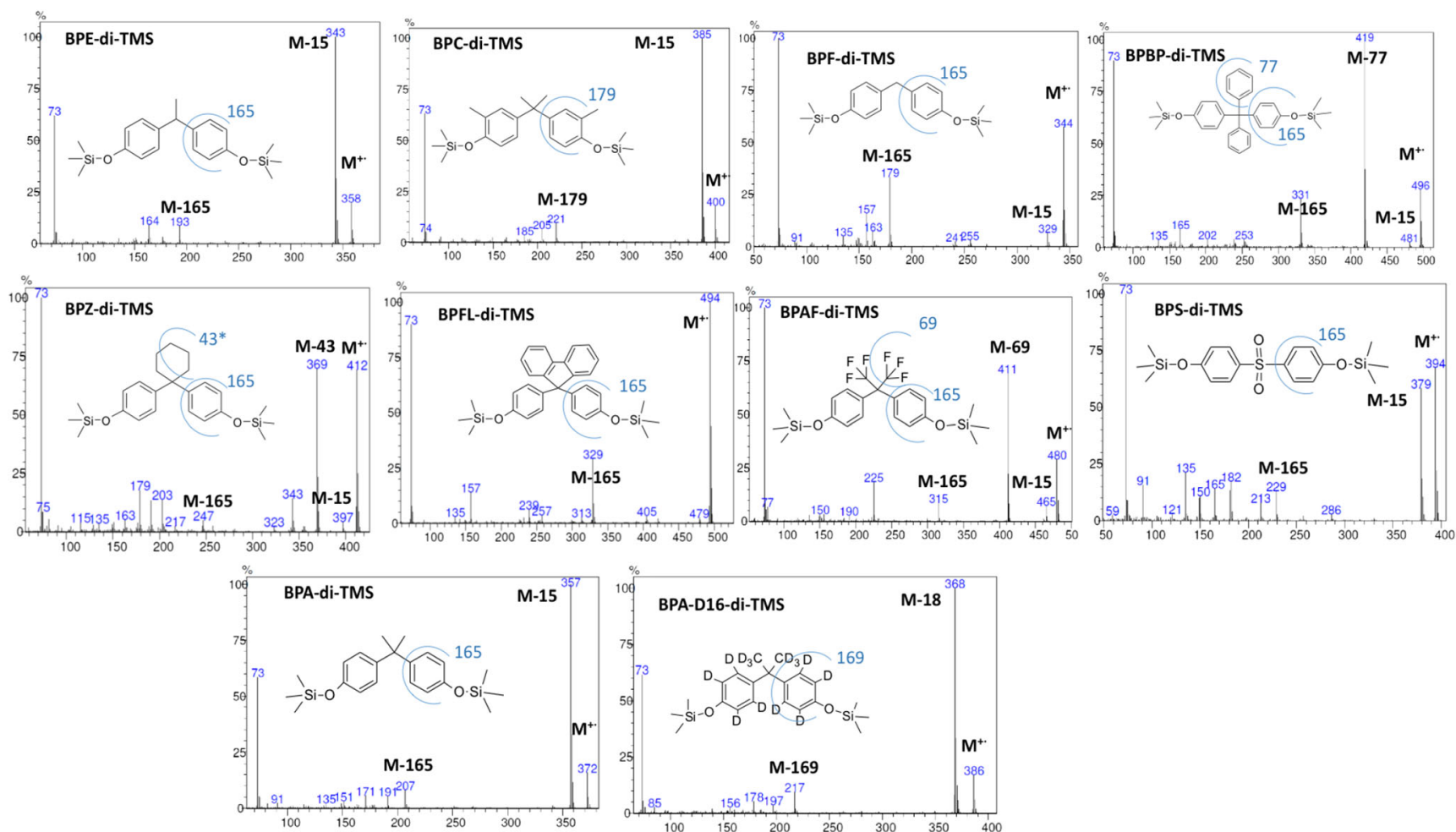

Fig. 2 The mass spectra and main fragmentation pathway found of nine bisphenol analogues and deuterated bisphenol in the form of trimethylsilyl (TMS) derivatives

$\mathrm{MeOH}$. The other modification was the application of the PSA sorbent at the top of the Strata-X column. The sample $\mathrm{pH}$ was not changed, as BPs are weak acids, and are non-ionized in natural waters. Figure 3 presents the values of extraction recovery (\%) of the 12 tested BPs (relative to the IS). The descriptions of test sets (1-5) are presented in Table 1. The notation HA means that humic acids were added to the sample. The 3HA set corresponds to the whole water analysis of BPs in environmental water due to the following reason: the water is rich in dissolved organic matter with adsorption

Table 2 The validation parameters of the SPE-GC/MS(SIM) method for the analysis of ten bisphenols in water samples (sample volume $100 \mathrm{~mL}$, internal standard - bisphenol A-D16)

\begin{tabular}{|c|c|c|c|c|c|}
\hline $\begin{array}{l}\text { Analyte } \\
\text { qualitative/ } \\
\text { reference } m / z\end{array}$ & $\begin{array}{l}\text { Correlation coefficient } \\
(\mathrm{MQL}-1000 \mathrm{ng} / \mathrm{L})\left(R^{2}\right)\end{array}$ & $\begin{array}{l}\text { Method trueness-method recovery } \\
\left(C_{\text {found }} C_{\text {spiked }} \times 100 \%\right)[\%] \pm \text { RSD }\end{array}$ & $\begin{array}{l}\text { Method } \\
\text { precision } \\
\text { (RSD) [\%] }\end{array}$ & $\begin{array}{l}\text { Method quantification } \\
\text { limit (MQL) [ng/L] }\end{array}$ & $\begin{array}{l}\text { Method detection } \\
\text { limit (MDL) [ng/L] }\end{array}$ \\
\hline $\begin{array}{l}\text { BPAF 411/480, } \\
\quad 465\end{array}$ & 0.9921 & $80-109 \pm 7$ & $1.0-7.3$ & 1.0 & 0.3 \\
\hline BPF 344/157 & 0.9948 & $78-105 \pm 11$ & $0.8-7.4$ & 5.0 & 1.7 \\
\hline BPE $343 / 358$ & 0.9970 & $90-133 \pm 9$ & $0.1-6.9$ & 1.0 & 0.3 \\
\hline BPA $357 / 372$ & 0.9985 & $96-120 \pm 8$ & $1.0-6.0$ & 5.0 & 1.7 \\
\hline BPC 385/400 & 0.9937 & $104-122 \pm 2$ & $0.6-9.3$ & 5.0 & 1.7 \\
\hline $\begin{array}{l}\text { BPA-DAC } \\
\quad 213 / 228,270, \\
312\end{array}$ & 0.9984 & $87-135 \pm 13$ & $3.0-13.0$ & 50.0 & 17.0 \\
\hline $\begin{array}{l}\text { BPZ 412/369, } \\
\quad 343\end{array}$ & 0.9959 & $97-111 \pm 7$ & $0.6-7.7$ & 1.0 & 0.3 \\
\hline $\begin{array}{l}\text { BPS 394/379, } \\
182\end{array}$ & 0.9990 & $87-104 \pm 7$ & $0.9-10.9$ & 5.0 & 1.7 \\
\hline $\begin{array}{l}\text { BPBP 419/331, } \\
\quad 496\end{array}$ & 0.9909 & $90-111 \pm 6$ & $1.8-8.9$ & 5.0 & 1.7 \\
\hline BPFL 494/329 & 0.9986 & $108-115 \pm 3$ & $2.6-10.1$ & 5.0 & 1.7 \\
\hline
\end{tabular}


potential (Murray and Örmec 2018) (the similarity of the structure of HAs to BPs was another reason). The precipitated HAs were removed before SPE by the filtration of the sample with glass fiber filters to prevent the SPE column from being blocked (often observed for non-filtered WW samples), the adsorbed fractions of BPs were eluted from the filters to the samples with $5 \mathrm{~mL}$ of $\mathrm{MeOH}$ (the concentration of organic solvent inside the sample was not higher than 5\%), then the full procedure of SPE was performed. Set 5 is the extraction of BPs from clear water without any pretreatment.

Generally, for BPF, BPE, BPA, BPC, BPZ, and BPS, the change in pretreatment and the addition of HAs have no effect on the extraction, and the extraction recovery was higher than $80 \%$, defined as the acceptable level. For BPAF, BPBP, and BPFL, it was noted that the addition of washing the filter is needed to obtain such a level (the sets without washing were 1, 1HA, 4 , and 4HA). The extraction of BPA-DAC was between 31 and $65 \%$ (medium 48\%), and the acceptable level of $80 \%$ was not reached. The extraction of BPA-DMA and BPA-DGE by SPE was ineffective, possibly due to the sorption of these analytes to the analytical equipment. Hydrolysis could also be an issue. On the other hand, the duration of the extraction (pretreatment + SPE) was not more than $4 \mathrm{~h}$, thereby much lower than the reported half-life of BPA-DGE in water (4.6 days (Lane et al. 2015)). The other reason for the low extraction of BPADMA and BPA-DGE is their high quantification limits by GC, mentioned in the previous paragraph. The application of the PSA sorbent did not disturb the extraction of BPAs, yet it was visually observed that it retained HAs (Fig. S4, Supplementary Information), thereby minimizing their presence inside the final extract. In the case of the analysis of WW samples, the use of PSA can lower the matrix effect in the GC analysis. In our previous work, the matrix effect in GC/MS was tested and was found to be connected mostly with the injection to GC (Caban et al. 2012), and any reduction in the injected extract composition was found to be beneficial for quantification by GC.

\section{Parameters of the validated SPE-GC/MS(SIM) analysis of the target bisphenols}

The SPE-GC/MS(SIM) method was developed for the purpose of the study and was not a modification of any existing method. The parameters of the validated method are presented in Table 2, and are applicable for both SW and WW. The MQLs were between 1 and $5 \mathrm{ng} / \mathrm{L}$, except for BPA-DAC, for which the MQL was $50 \mathrm{ng} / \mathrm{L}$. The highest calibration level was $1000 \mathrm{ng} / \mathrm{L}$ for each of the BPs. For BPA-DMA and BPADGE, the methodological parameters were not presented because of their low extraction recovery from water samples by SPE; they were rejected from the group of analytes. In the blank samples, BPA was detected with a concentration < MQL. The within-day method recovery was acceptable, and the range of recovery values for all tested levels was 87 $133 \%$. The precision, presented as RSD, was below $13 \%$.

Generally, the MQLs of the analysis of BPA by the LC/MS and GC/MS techniques are similar (Ros et al. 2015). Table 3 presents a comparison of the method developed here to those found in the literature for more than 7 analogues of BPs in one run. The recoveries in this work are generally higher. The MQLs are within the literature values (resulting from the sample volume used for the analysis).

\section{The concentrations of BPs found in wastewaters}

In Table 4, the concentrations of BPA and BPS (ng/L), the only analytes found, are presented (rounded to a number with no decimal places). Some of them were above the upper validation level of $1000 \mathrm{ng} / \mathrm{L}$. The substantial lower

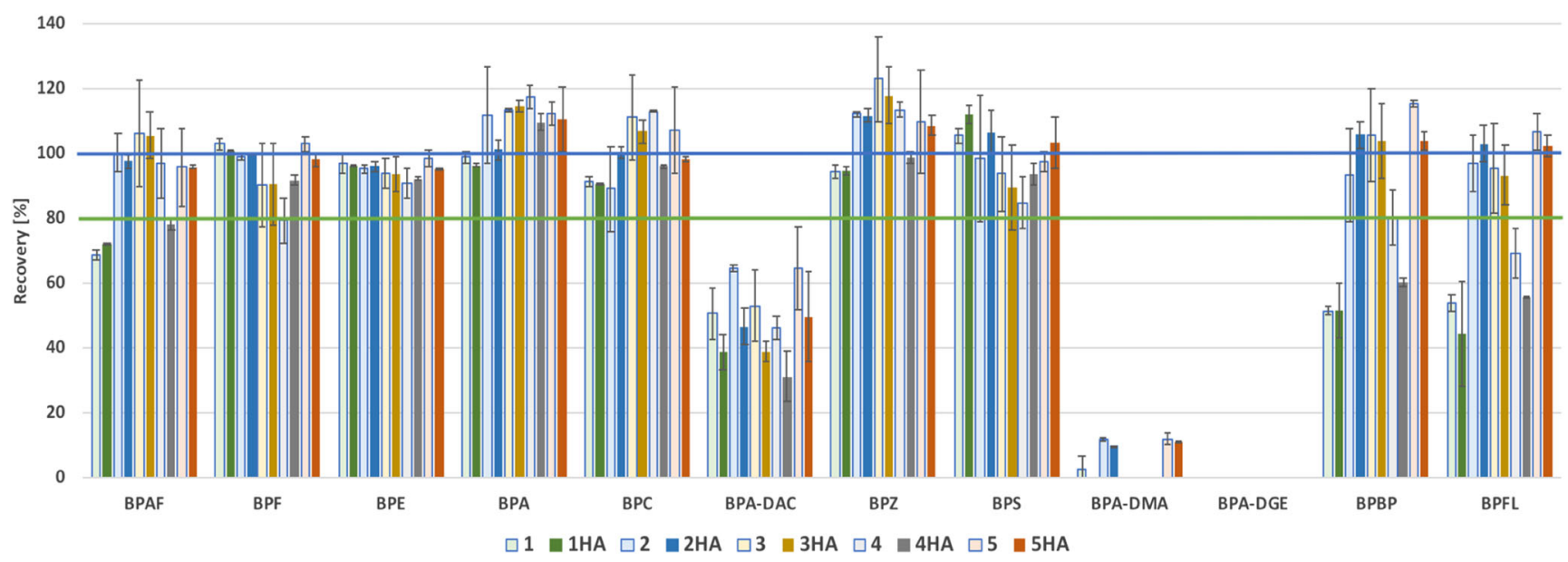

Fig. 3 The extraction recovery [\%] of the tested twelve bisphenols in relation to solid-phase extraction performance by ten sets (sets 1 to $5 \mathrm{HA}$, presented in Table 1, the level of acceptable recovery of $80 \%$ and desired recovery of $100 \%$ were marked by lines) 
Table 3 The comparison of the MQLs and recoveries from the analysis of bisphenol analogues determined in this work to others found in the literature

\begin{tabular}{|c|c|c|c|c|c|}
\hline Number of bisphenols: targets & Method & $\begin{array}{l}\text { Sample } \\
\text { volume }\end{array}$ & MQL [ng/L] & $\begin{array}{l}\text { Method } \\
\text { recovery }[\%]\end{array}$ & Reference \\
\hline $\begin{array}{l}\text { 10: BPAF, BPE, BPF, BPA, BPC, BPS, BP-DAC, BPZ, } \\
\text { BPBP, BPFL }\end{array}$ & SPE-GC/MS(SIM) & $100 \mathrm{~mL}$ & $\begin{array}{l}1-5 \text { (except } 50 \text { for } \\
\text { BP-DAC) }\end{array}$ & $87-133$ & This work \\
\hline 8: BPAF, BPAP, BPB, BPC, BPE, BPF, BPS, BPZ & SPE-GC/MS(SIM) & $2 \mathrm{~L}$ & $0.465-4.13$ & $56-100$ & $\begin{array}{l}\text { Česen et al. } \\
\text { (2018) }\end{array}$ \\
\hline $\begin{array}{l}\text { 14: BPA, BPF, BPS, BPAF, BPAP, BPP, BPB, BPZ, } \\
\text { BPA-DGE (six related compounds) }\end{array}$ & SPE-LC/MS/MS & $100 \mathrm{~mL}$ & $1-100$ & $61-117$ & $\begin{array}{l}\text { Xue and Kannan } \\
\text { (2019) }\end{array}$ \\
\hline 7: BPA, BPAF, BPB, BPE, BPF, BPS, BPZ & SPE-LC/MS/MS & $500 \mathrm{~mL}$ & $0.043-2.43$ & $43-90$ & Sun et al. (2017) \\
\hline
\end{tabular}

concentrations were found in the treated WWs compared with the raw WWs, which is in accordance with literature information regarding the relatively high performance of the active sludge process in the removal of bisphenols (Wang et al. 2019).

In the study performed in Ljubljana (Česen et al. 2018), from the eight tested BPs (without BPA measurement), the only one found in treated WW was BPS (40 ng/L), similar to our work. In the review from 2018, it was presented that BPA and BPS are the BPs with the highest concentrations worldwide, while the other ones (BPAF, BPAP, BPB, BPP, BPF, BPZ) are sporadic (Noszczyńska and Piotrowska-Seget 2018). BPA, BPS, and BPF were found with similar detection frequency in the WW sampled in China (Song et al. 2014). In our work, BPF was found to be below the MDL.

BPS is currently used as a safe replacement for BPA (Becerra and Odermatt 2012), but there are reports which present its negative impact on human health (Thoene et al. 2018; Qiu et al. 2019). BPS has an EDC character, compared with BPA (lower or higher depending on the study (Chen et al. 2016; Hąc-Wydro et al. 2019; Lee et al. 2019)). There are several origins of BPS in WWs. One of them is recycled paper used as toilet paper (Pivnenko et al. 2018). The application, occurrence, safety, and biodegradation of BPs are presented in the review by Noszczyńska and Piotrowska-Seget (Noszczyńska and Piotrowska-Seget 2018). The ecotoxicology of mixtures of BPs shows a significant endocrine threat (Owczarek et al. 2018). Thereby, the monitoring of BPA together with its analogues should be performed more often.

\section{The concentrations of BPs found in surface water}

In Table 5, the concentrations of BPA and BPS are presentedsimilarly to the WW samples, only those two analytes were detected. The chromatographic peaks of BPA and BPS in blanks, standard samples, and various extracts are presented in Fig. S5 (Supplementary Information). The concentrations found were relatively high compared with the previously presented concentrations for WWs (Table 4), but lower than the literature data for SW, presented in Table 5. Special attention should be given to sample 2, as Kozacki Stream is partially supplied by water from the landfill (its location is presented in Fig. S2, Supplementary Information). In sample 3, the concentration of BPA was $3113 \mathrm{ng} / \mathrm{L}$, thereby about twice as high as in raw WW from Gdansk-Wschód WWTP (Table 4). In the work performed in 2019 in the mentioned landfill, BPA was found in a concentration of between 856 and $2202 \mu \mathrm{g} / \mathrm{L}$ in the leachate from the old cell (currently not operated, with old barrier technology) (Wilk et al. 2019), about 8 times higher than the concentration in our study. The presence of the accelerated concentration of BPA in Kozacki Stream can suggest that the efforts

Table 4 The concentrations of BPA and BPS (ng/L) found in the tested samples of wastewater (WW) in comparison to the literature data

\begin{tabular}{|c|c|c|c|c|c|c|c|c|c|c|}
\hline \multirow[t]{2}{*}{ Compound } & \multicolumn{2}{|c|}{$\begin{array}{l}\text { WWTP Gdansk- } \\
\text { Wschód, Poland }\end{array}$} & \multicolumn{2}{|c|}{$\begin{array}{l}\text { WWTP Gniewino, } \\
\text { Poland }\end{array}$} & \multicolumn{2}{|c|}{$\begin{array}{l}\text { WWTP Swarzewo, } \\
\text { Poland }\end{array}$} & \multicolumn{2}{|c|}{$\begin{array}{l}\text { WWTP New York, USA, } 2018 \\
\text { (Xue and Kannan 2019) }\end{array}$} & \multicolumn{2}{|c|}{$\begin{array}{l}\text { WWTP Xiamen, China, } \\
2016 \text { (Sun et al. 2017) }\end{array}$} \\
\hline & $\begin{array}{l}\text { Raw } \\
\text { WW }\end{array}$ & $\begin{array}{l}\text { Treated } \\
\text { WW }\end{array}$ & $\begin{array}{l}\text { Raw } \\
\text { WW }\end{array}$ & $\begin{array}{l}\text { Treated } \\
\text { WW }\end{array}$ & $\begin{array}{l}\text { Raw } \\
\text { WW }\end{array}$ & $\begin{array}{l}\text { Treated } \\
\text { WW }\end{array}$ & Raw WW & Treated WW & Raw WW & $\begin{array}{l}\text { Treated } \\
\text { WW }\end{array}$ \\
\hline BPA & 1465 & 42 & 1194 & 16 & 782 & 61 & < MQL-8420 & $<$ MQL-3340 & $\begin{array}{r}\text { Median } \\
1318\end{array}$ & $\begin{array}{c}\text { Median } \\
177\end{array}$ \\
\hline BPS & 1249 & 10 & 595 & $<\mathrm{MDL}$ & 1045 & $<\mathrm{MDL}$ & < MQL-649 & MQL-420 & Median 48 & Median 4 \\
\hline
\end{tabular}




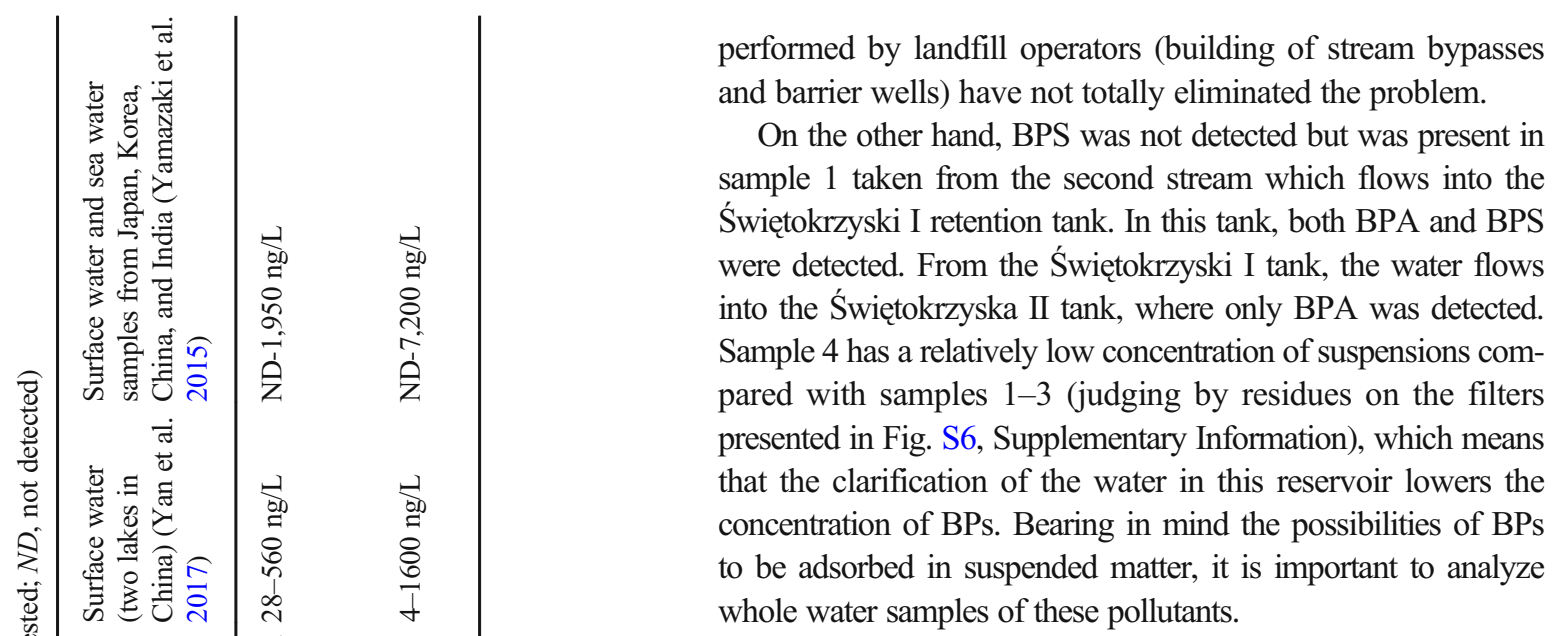

\section{Conclusions}

This study shows the advantages and disadvantages of GC/MS as a tool for the quantification of mixtures of BPs. There are limits regarding the application of GC for BPA diglycidyl ether, BPA diacetate, and BPA dimethacrylate - compounds without the possibilities of trimethylsilylation, as they can decompose in the hot injector. The TMS derivatives of BPs give good mass spectra for qualitative and quantitative analysis by the SIM mode of mass spectra recording. The application of the PSA sorbent improves SPE - reducing the matrix component without a reduction in the extraction recovery of analytes. The validation of SPEGC/MS(SIM) has proved its applicability for the determination of whole water concentrations of BPs in WW and SW. Despite the omnipresence of BPA, BPS was found in levels similar to BPA. This should raise attention since BPS has a similar EDC character to BPA, but is rather overlooked in risk assessment.

Acknowledgments Acknowledgments are given to the WWTPs in Gdańsk, Swarzewo, and Gniewino for providing samples.

\section{Compliance with ethical standards}

Conflict of interest The authors declare that they have no conflict of interest.

Open Access This article is licensed under a Creative Commons Attribution 4.0 International License, which permits use, sharing, adaptation, distribution and reproduction in any medium or format, as long as you give appropriate credit to the original author(s) and the source, provide a link to the Creative Commons licence, and indicate if changes were made. The images or other third party material in this article are included in the article's Creative Commons licence, unless indicated otherwise in a credit line to the material. If material is not included in the article's Creative Commons licence and your intended use is not permitted by statutory regulation or exceeds the permitted use, you will need to obtain permission directly from the copyright holder. To view a copy of this licence, visit http://creativecommons.org/licenses/by/4.0/. 


\section{References}

Almeida S, Raposo A, Almeida-González M, Carrascosa C (2018) Bisphenol A: food exposure and impact on human health. Compr Rev Food Sci Food Saf 17:1503-1517. https://doi.org/10.1111/ $1541-4337.12388$

Becerra V, Odermatt J (2012) Detection and quantification of traces of bisphenol $\mathrm{A}$ and bisphenol $\mathrm{S}$ in paper samples using analytical pyrolysis-GC/MS. Analyst 137:2250-2259. https://doi.org/10.1039/ c2an15961a

Caban M, Stepnowski P, Kwiatkowski M, Migowska N, Kumirska J (2011) Determination of $\beta$-blockers and $\beta$-agonists using gas chromatography and gas chromatography - mass spectrometry - a comparative study of the derivatization step. J Chromatogr A 1218: 8110-8122. https://doi.org/10.1016/j.chroma.2011.08.093

Caban M, Migowska N, Stepnowski P, Kwiatkowski M, Kumirska J (2012) Matrix effects and recovery calculations in analyses of pharmaceuticals based on the determination of $\beta$-blockers and $\beta$ agonists in environmental samples. J Chromatogr A 1258:117127. https://doi.org/10.1016/j.chroma.2012.08.029

Caban M, Czerwicka M, Łukaszewicz P, Migowska N, Stepnowski P, Kwiatkowski M, Kumirska J (2013a) A new silylation reagent dimethyl(3,3,3-trifluoropropyl)silyldiethylamine for the analysis of estrogenic compounds by gas chromatography-mass spectrometry. J Chromatogr A 1301:215-224. https://doi.org/10.1016/j.chroma. 2013.05.073

Caban M, Mioduszewska K, Stepnowski P, Kwiatkowski M, Kumirska J (2013b) Dimethyl(3,3,3-trifluoropropyl)silyldiethylamine-a new silylating agent for the derivatization of $\beta$-blockers and $\beta$-agonists in environmental samples. Anal Chim Acta 782:75-88. https://doi. org/10.1016/j.aca.2013.04.018

Caban M, Mioduszewska K, Łukaszewicz P, Migowska N, Stepnowski P, Kwiatkowski M, Kumirska J (2014) A new silylating reagent dimethyl(3,3,3-trifluoropropyl)silyldiethylamine - for the derivatisation of non-steroidal anti-inflammatory drugs prior to gas chromatography-mass spectrometry analysis. J Chromatogr A 1346: 107-116. https://doi.org/10.1016/j.chroma.2014.04.054

Cabaton N, Dumont C, Severin I, Perdu E, Zalko D, Cherkaoui-Malki M, Chagnon MC (2009) Genotoxic and endocrine activities of bis(hydroxyphenyl)methane (bisphenol F) and its derivatives in the HepG2 cell line. Toxicology 225:15-24. https://doi.org/10. 1016/j.tox.2008.09.024

Česen M, Lenarčič K, Mislej V, Levstek M, Kovačič A, Cimrmančič B, Uranjek N, Kosjek T, Heath D, Dolenc MS, Heath E (2018) The occurrence and source identification of bisphenol compounds in wastewaters. Sci Total Environ 616-617:744-752. https://doi.org/ 10.1016/j.scitotenv.2017.10.252

Chen D, Kannan K, Tan H, Zheng Z, Feng YL, Wu Y, Widelka M (2016) Bisphenol analogues other than BPA: environmental occurrence, human exposure, and toxicity - a review. Environ Sci Technol 50: 5438-5453. https://doi.org/10.1021/acs.est.5b05387

CITAC / EURACHEM (2002) CITAC/EURACHEM GUIDE guide to quality in analytical chemistry an aid to accreditation

Corrales J, Kristofco LA, Steele WB, Yates BS, Breed CS, Williams ES, Brooks BW (2015) Global assessment of bisphenol A in the environment: review and analysis of its occurrence and bioaccumulation. Dose-Response An Int J 13:1-29. https://doi.org/10.1177/ 1559325815598308

del Olmo M, González-Casado A, Navas NA, Vilchez JL (1997) Determination of bisphenol A in water by gas chromatographymass spectrometry. Anal Chim Acta 346:87-92

Durán-Alvarez JC, Becerril-Bravo E, Silva V et al (2009) The analysis of a group of acidic pharmaceuticals, carbamazepine , and potential endocrine disrupting compounds in wastewater irrigated soils by gas chromatography - mass spectrometry. Talanta 78:1159-1166. https://doi.org/10.1016/j.talanta.2009.01.035

Gercken J, Caban M, Pettersson M, et al (2018) Hazardous substance occurrence in Baltic sea pilot municipalities major output from the tracking and ranking for prioritisation of sources in Non Haz City

Hacc-Wydro K, Połeć K, Broniatowski M (2019) The comparative analysis of the effect of environmental toxicants: bisphenol A, S and $\mathrm{F}$ on model plant, fungi and bacteria membranes. The studies on multicomponent systems. J Mol Liq 289:111136. https://doi.org/10. 1016/j.molliq.2019.111136

IUPAC (2002) IUPAC Technical Report - Harmonized guidelines for single-laboratory validation of methods of analysis

Kalmykova Y, Björklund K, Strömvall AM, Blom L (2013) Partitioning of polycyclic aromatic hydrocarbons, alkylphenols, bisphenol A and phthalates in landfill leachates and stormwater. Water Res 47:13171328. https://doi.org/10.1016/j.watres.2012.11.054

Lane RF, Adams CD, Randtke SJ, Carter RE (2015) Bisphenol diglycidyl ethers and bisphenol A and their hydrolysis in drinking water. Water Res 72:331-339. https://doi.org/10.1016/j.watres.2014.09.043

Lee S, Kim C, Shin H, Kho Y, Choi K (2019) Comparison of thyroid hormone disruption potentials by bisphenols $\mathrm{A}, \mathrm{S}, \mathrm{F}$, and $\mathrm{Z}$ in embryo-larval zebrafish. Chemosphere 221:115-123. https://doi. org/10.1016/j.chemosphere.2019.01.019

Markham DA, Mcnett DA, Birk JH et al (1998) Quantitative determination of bisphenol A in river water by cool on-column injection-gas chromatography-mass spectrometry. J Environ Anal Chem 69:8398

Murphy L, Mérida-Ortega Á, Cebrián ME, Hernández-Garciadiego L, Gómez-Ruiz H, Gamboa-Loira B, López-Carrillo L (2019) Exposure to bisphenol A and diabetes risk in Mexican women. Environ Sci Pollut Res 26:26332-26338. https://doi.org/10.1007/ s11356-019-05731-9

Murray A, Örmec B (2018) Competitive effects of humic acid and wastewater on adsorption of Methylene Blue dye by activated carbon and non-imprinted polymers. J Environ Sci 66:310-317

Noszczyńska M, Piotrowska-Seget Z (2018) Bisphenols: application, occurrence, safety, and biodegradation mediated by bacterial communities in wastewater treatment plants and rivers. Chemosphere 201: 214-223. https://doi.org/10.1016/j.chemosphere.2018.02.179

Oca ML, Ortiz MC, Herrero A, Sarabia LA (2013) Optimization of a GC/ MS procedure that uses parallel factor analysis for the determination of bisphenols and their diglycidyl ethers after migration from polycarbonate tableware. Talanta 106:266-280. https://doi.org/10.1016/ j.talanta.2012.10.086

Owczarek K, Kudłak B, Simeonov V, Mazerska Z, Namieśnik J (2018) Binary mixtures of selected bisphenols in the environment: their toxicity in relationship to individual constituents. Molecules 23: 3226. https://doi.org/10.3390/molecules 23123226

Pivnenko K, Laner D, Astrup TF (2018) Dynamics of bisphenol A (BPA) and bisphenol S (BPS) in the European paper cycle: need for concern? Resour Conserv Recycl 133:278-287. https://doi.org/10. 1016/j.resconrec.2018.01.021

Qiu W, Zhan H, Hu J, Zhang T, Xu H, Wong M, Xu B, Zheng C (2019) The occurrence, potential toxicity, and toxicity mechanism of bisphenol S, a substitute of bisphenol A: a critical review of recent progress. Ecotoxicol Environ Saf 173:192-202. https://doi.org/10. 1016/j.ecoenv.2019.01.114

Ros O, Vallejo A, Olivares M et al (2015) Microextraction with polyethersulfone for bisphenol-A, alkylphenols and hormones determination in water samples by means of gas chromatography - mass spectrometry and liquid chromatography - tandem mass spectrometry analysis. Talanta 134:247-255. https://doi.org/10.1016/j. talanta.2014.11.015

Sadkowska J, Caban M, Chmielewski M, Stepnowski P, Kumirska J (2017) Environmental aspects of using gas chromatography for determination of pharmaceutical residues in samples characterized by 
different composition of the matrix. Arch Environ Prot 43:3-9. https://doi.org/10.1515/aep-2017-0028

Song S, Song M, Zeng L, Wang T, Liu R, Ruan T, Jiang G (2014) Occurrence and profiles of bisphenol analogues in municipal sewage sludge in China. Environ Pollut 186:14-19. https://doi.org/10. 1016/j.envpol.2013.11.023

Sun Q, Wang Y, Li Y, Ashfaq M, Dai L, Xie X, Yu CP (2017) Fate and mass balance of bisphenol analogues in wastewater treatment plants in Xiamen City, China. Environ Pollut 225:542-549. https://doi.org/ 10.1016/j.envpol.2017.03.018

Szczepańska N, Kubica P, Kudłak B, Namieśnik J, Wasik A (2019) Stabilities of bisphenol A diglycidyl ether, bisphenol F diglycidyl ether, and their derivatives under controlled conditions analyzed using liquid chromatography coupled with tandem mass spectrometry. Anal Bioanal Chem 411:6387-6398. https://doi.org/10.1007/ s00216-019-02016-5

Thoene M, Rytel L, Nowicka N, Wojtkiewicz J (2018) The state of bisphenol research in the lesser developed countries of the EU: a mini-review. Toxicol Res (Camb) 7:371-380. https://doi.org/10. 1039/c8tx00064f

U.S. Environmental Protection Agency (2015) Bisphenol A alternatives in thermal paper - final report

Vahedi M, Saeedi A, Poorbaghi SL, Sepehrimanesh M, Fattahi M (2016) Metabolic and endocrine effects of bisphenol A exposure in market seller women with polycystic ovary syndrome. Environ Sci Pollut Res 23:23546-23550. https://doi.org/10.1007/s11356-016-7573-5

Viñas P, Campillo N, Martínez-Castillo N, Hernández-Córdoba M (2010) Comparison of two derivatization-based methods for solid-phase microextraction-gas chromatography-mass spectrometric determination of bisphenol $\mathrm{A}$, bisphenol $\mathrm{S}$ and biphenol migrated from food cans. Anal Bioanal Chem 397:115-125

Wang H, Zhua L, Zhang J et al (2019) Insights into removal mechanisms of bisphenol A and its analogues in municipal wastewater treatment plants. Sci Total Environ 692:107-116. https://doi.org/10.1016/j. scitotenv.2019.07.134

Warner GR, Flaws JA (2018) Common bisphenol A replacements are reproductive toxicants. Nat Rev Endocrinol 14:691-692. https://doi. org/10.1038/s41574-018-0113-2
Wilczewska K, Namiesnik J, Wasik A (2016) Troubleshooting of the determination of bisphenol A at ultra-trace levels by liquid chromatography and tandem mass spectrometry. Anal Bioanal Chem 408: 1009-1013. https://doi.org/10.1007/s00216-015-9215-z

Wilk BK, Fudala-Ksiazek S, Szopińska M, Luczkiewicz A (2019) Landfill leachates and wastewater of maritime origin as possible sources of endocrine disruptors in municipal wastewater. Environ Sci Pollut Res 26:25690-25701. https://doi.org/10.1007/s11356019-05566-4

Xue J, Kannan K (2019) Mass flows and removal of eight bisphenol analogs, bisphenol A diglycidyl ether and its derivatives in two wastewater treatment plants in New York State, USA. Sci Total Environ 648:442-449. https://doi.org/10.1016/j.scitotenv.2018.08. 047

Xu-Liang C (2019) Letter to the Editor regarding "Comparison of two derivatization-based methods for solid-phase microextraction-gas chromatography-mass spectrometric determination of bisphenol A, bisphenol S, and biphenol migrated from food cans". Anal Bioanal Chem 411:287-288. https://doi.org/10.1007/s00216-010-3464-7

Yamamoto T, Yasuhara A, Shiraishi H, Nakasugi O (2001) Bisphenol A in hazardous waste landfill leachates. Chemosphere 42:415-418. https://doi.org/10.1016/S0045-6535(00)00079-5

Yamazaki E, Yamashita N, Taniyasu S, Lam J, Lam PKS, Moon HB, Jeong Y, Kannan P, Achyuthan H, Munuswamy N, Kannan K (2015) Ecotoxicology and environmental safety bisphenol A and other bisphenol analogues including BPS and BPF in surface water samples from Japan, China, Korea and India. Ecotoxicol Environ Saf 122:565-572. https://doi.org/10.1016/j.ecoenv.2015.09.029

Yan Z, Liu Y, Yan K, Wu S, Han Z, Guo R, Chen M, Yang Q, Zhang S, Chen J (2017) Bisphenol analogues in surface water and sediment from the shallow Chinese freshwater lakes: occurrence, distribution, source apportionment, and ecological and human health risk. Chemosphere 184:318-328. https://doi.org/10.1016/j. chemosphere.2017.06.010

Publisher's note Springer Nature remains neutral with regard to jurisdictional claims in published maps and institutional affiliations. 